\title{
Lusisersily
}

\section{PRELIMINARY-REPORT ON A NEW TECHNIQUE TO AID DIAGNOSIS OF SOME DISORDERS FOUND IN HANDS}

WALLACE, RGH., MOLLAN, RAB., \& Kernohan, G. (1985). PRELIMINARY-REPORT ON A NEW TECHNIQUE TO AID DIAGNOSIS OF SOME DISORDERS FOUND IN HANDS. Journal of Hand Surgery (European Volume), 10B(2), 269-272. https://doi.org/10.1016/0266-7681(85)90038-5

Link to publication record in Ulster University Research Portal

\section{Published in:}

Journal of Hand Surgery (European Volume)

Publication Status:

Published (in print/issue): 01/01/1985

DOI:

10.1016/0266-7681(85)90038-5

\section{Document Version}

Publisher's PDF, also known as Version of record

\section{General rights}

Copyright for the publications made accessible via Ulster University's Research Portal is retained by the author(s) and / or other copyright owners and it is a condition of accessing these publications that users recognise and abide by the legal requirements associated with these rights.

\section{Take down policy}

The Research Portal is Ulster University's institutional repository that provides access to Ulster's research outputs. Every effort has been made to ensure that content in the Research Portal does not infringe any person's rights, or applicable UK laws. If you discover content in the Research Portal that you believe breaches copyright or violates any law, please contact pure-support@ulster.ac.uk. 


\title{
Preliminary Report on a New Technique to Aid Diagnosis of Some Disorders Found in Hands
}

\author{
R. G: H. WALLACE, Liverpool, R. A. B. MOLLAN and W. G. KERNOHAN, Belfast \\ From the Queen's University, Belfast.

\begin{abstract}
This preliminary report proposes to show that an objective auscultatory method exists as an aid to diagnosis of some hand conditions. The signals so produced are both distinctive and reproducible: The conditions investigated were:- Cavitation finger clicks; Trigger finger;
\end{abstract} \\ normal crepitus and the crepitus of de Quervain's tenosynovitis.
}

\begin{abstract}
Auscultation is a non-invasive aid to diagnosis which has been used for many centuries. Its first documentation is to be found in the Hippocratic Collection (400 B.C.). Following Laennec's development of the stethoscope, Lisfranc described how a fracture could be distinguished from a dislocation by mediate auscultation. Walters (1929) described auscultation of several joints using a stethoscope, comparing his results by age and sex, but not proposing it as a diagnostic technique. Steindler (1937) investigated several knee abnormalities using a cardiophone and although he claimed the technique useful for localising the site of the abnormality, he did not claim it to be diagnostic. He concluded that interpretation of the results was difficult because of extra-osseous and extra-articular noise. The use of the microphone for orthopaedic auscultation was complicated by skin friction noise and ambient noise, also, the frequency and dynamic range of microphones were unsuitable for the low frequency vibrations encountered from human joints. The piezo-electric accelerometer has now been shown to be a more suitable sensor for investigation of human vibration emission (Mollan, 1984).
\end{abstract}

The snapping or cracking sounds produced in human joints, which are sometimes audible, has, for many years, been a puzzle (B.M.J., 1969). It has been suggested that such cracking is due to a sudden vaporisation within a joint cavity under tension (Roston, 1947). Unsworth described the vaporisation as a cavitation (Unsworth, 1971), and later made a distinction between the intra-articular cavitation cracks and the extra-articular cracks caused by ligaments or tendons passing over bony prominences (Unsworth, 1974).

In his thesis on Vibration Emission in Bone and Joints, Mollan described the development of a system for detection of human vibration emission using piezoelectric accelerometers to detect such sounds (Mollan, 1981). The signal detected was stored on magnetic tape for subsequent analysis, using a frequency analyser. The data were then digitised, using a microprocessor to

Received for publication July, 1984.

R. G. H. Wallace, F.R.C.S., Royal Liverpool Hospital, Prescot Street, Liverpool. store, access and analyse vibrations occurring in the pelvis of neonates during Barlow and Ortolani tests. This resulted in a very significant diagnostic tool for the early detection of Congenital Dislocation of the Hip (Cowie, 1983).

This technique has been extended to the hand and it is our aim to show that, certain mechanical disorders produce distinctive, reproducible vibrations specific to that disorder.

\section{Material and Methods}

The accelerometer (Figure 1) is an electromechanical transducer which produces an output voltage proportional to the acceleration to which it is subjected. Its use as a detector was ideally suitable (Mollan, 1984) because:-

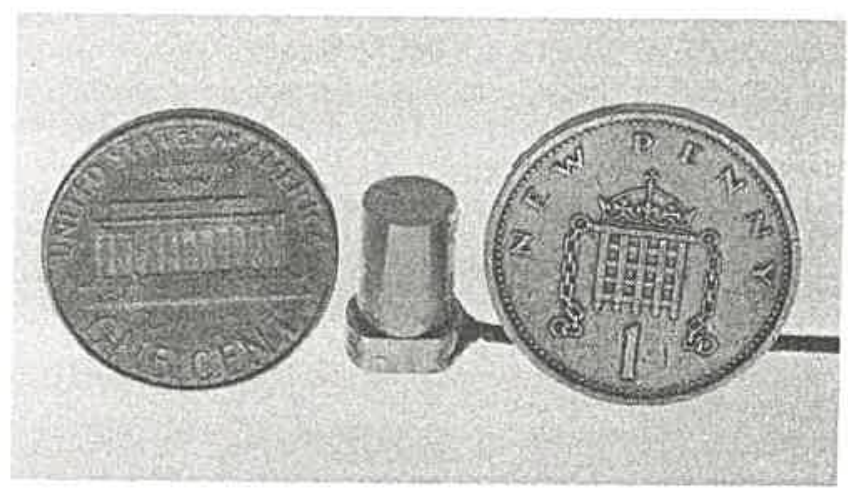

Fig. 1 The Accelerometer compared to penny and cent.

1. It was small, influencing the response of the vibration emission as little as possible. It also permitted precise source location, as opposed to detection over a large area.

2. It minimised the problem of acoustic impedance at the skin-air interphase, thus reducing the problem of background noise.

3. The frequency range $(1-30,000 \mathrm{HZ})$ was suitable for human vibration emission, and its response was both sensitive and directional.

We used a B.B.N. series 501 piezoelectric accelerometer of mass $1.8 \mathrm{~g}$. 
The positioning of the accelerometer was important. It was placed as near to the source as possible without hindering movement. Joint vibrations were best detected over adjacent bony prominences, while vibrations emitted from tendon sheaths were best detected where they run superficially.

The accelerometer was attached at an appropriate site using adhesive tape and, in order to reduce artifact, the accelerometer cable was also secured with tape. The precise positioning of the detector depended on the condition being investigated. For joint clicks, the accelerometer was placed over the middle of the appropriate metacarpal on the extensor aspect, while, for trigger finger, it was found best to place the accelerometer over an affected tendon at the level of the distal palmar crease. For detection of crepitus produced by the normal tendon sheath and that produced by deQuervain's tenosynovitis, the accelerometer was placed over the common sheath of the long abductor and short extensor at the level of the radial styloid.

A pre-amplifier was used to boost the signal from the accelerometer: this signal was then recorded on an instrumentation tape recorder. The signal was subsequently analysed using a narrow band spectrum analyser, which displayed the time signal and a frequency analysis. An X-Y plotter was also used to provide a hard copy of the frequency analysis (Figure 2). Further analysis, using a microprocessor, with hard copy of the result on a dot matrix printer, was obtained. A programme was available to enable the microprocessor to determine the peak frequency and energy values for a given signal.

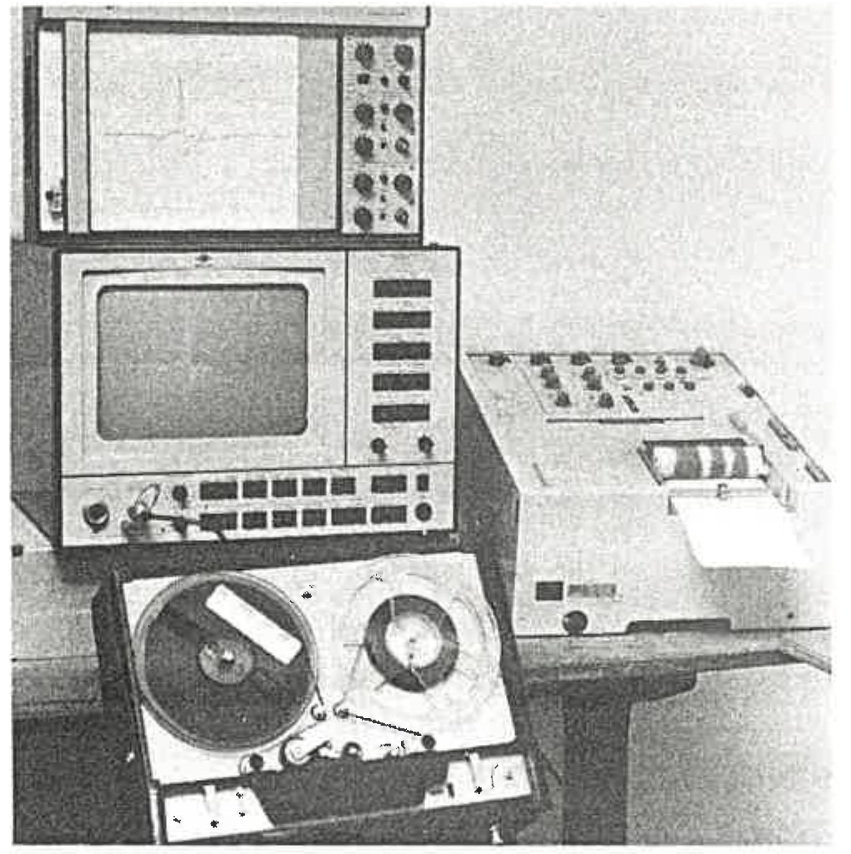

Fig. 2 The analysis equipment.
Five subjects were chosen who could produce cavitation clicks 'by forced flexion of the metacarpophalangeal joints. Fifty such clicks were recorded at random.

Three subjects with trigger fingers were investigated during flexion and extension. The signals produced by both flexion and extension were recorded.

Recordings were made from five subjects with deQuervain's tenosynovitis, during active flexion and extension of the thumb.

\section{Results}

An example of the waveform produced by a cavitation click is shown in Figure 3. This wave form was quite distinct and found to be reproducible in this episodic form. Signal analysis for acceleration range, R.M.S. and peak frequency are shown in Table 1, giving mean values and standard deviation. While peak frequencies varied considerably, the acceleration range varied less and the R.M.S. (giving an indication of the power of the waveform) showed a small standard deviation.

TABLE 1

Cavitation Click

\begin{tabular}{llll}
\hline & $\begin{array}{l}\text { Acceleration } \\
\text { Range } \\
(\mathrm{m} / \mathrm{s} / \mathrm{s})\end{array}$ & R.M.S. & $\begin{array}{l}\text { Peak } \\
\text { Frequency } \\
(\mathrm{HZ} / \mathrm{s} / \mathrm{s})\end{array}$ \\
\hline Mean & 85.447 & 01.466 & 537.50 \\
Standard Deviation & 67.362 & 00.783 & 854.34 \\
\hline
\end{tabular}

The waveform of signals produced by a subject with a trigger finger was found to be episodic, like that recorded from a cavitation click, but quite distinct from such a click. Examples are shown in Figure 4. The signals recorded in flexion were distinct from those recorded in extension, the former having an initial peak positive and the latter, an initial peak negative waveform. The waveform was also found to be remarkably constant for repeated triggering, as can be seen in Figure 4, which shows examples from four triggering episodes in one patient.

Table 2 shows the results of signal analysis for both flexion and extension in each of the three subjects tested (the figures are for ten signals in each case). As can be seen, the standard deviations are low in each case. Thus the waveform can be said to be specific for each subject, but retains sufficient similarity between subjects to be diagnostic of the condition. Subsequent surgery in each of the three patients confirmed the diagnosis.

During recording, a background waveform of low amplitude periodic type was noted, which could not be detected by palpation. It was called "low amplitude crepitus", and considered normal. An example of this 


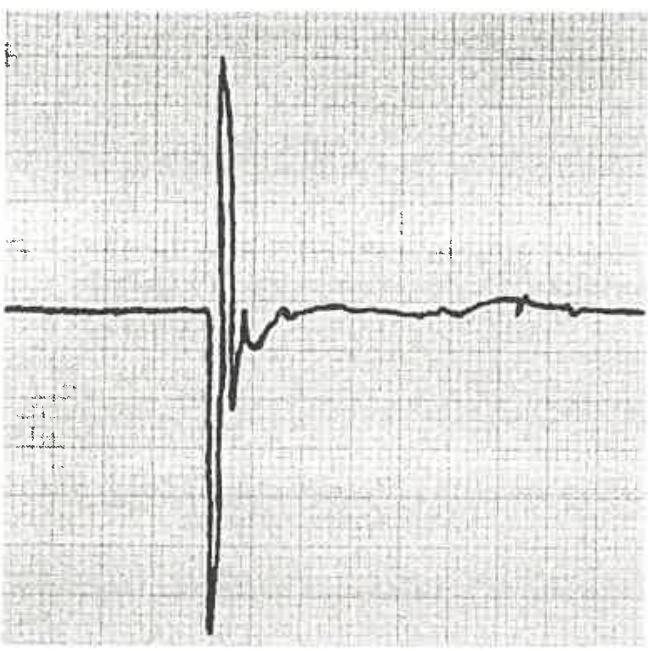

Fig. 3 Finger Click $(25 \mathrm{~mm} / \mathrm{sec}$.).

waveform is shown in Figure 5 and signal analysis is shown in Table 3.

The palpable crepitus of deQuervain's tenosynovitis resulted in a distinctly different periodic waveform of higher frequency. An example of the waveform is shown in Figure 6 and the results of signal analysis are presented in Table 4.

The waveform of crepitus of tenosynovitis is distinct from that of normal low amplitude crepitus, and reproducible, not only in one subject but also in other subjects with a similar condition.

\section{Conclusion}

It is possible to produce distinctive and reproducible vibration signals from the hand, and it is clear that these signals are diagnostic for the conditions investigated. The technique is complicated, and the apparatus is expensive and not portable, however the same process of digitisation which was followed to produce a bedside screener for Congenital Dislocation of the Hip could be followed to produce a diagnostic machine for hand signals. The signals could be recorded on floppy disc for more advanced analysis and bulk storage.

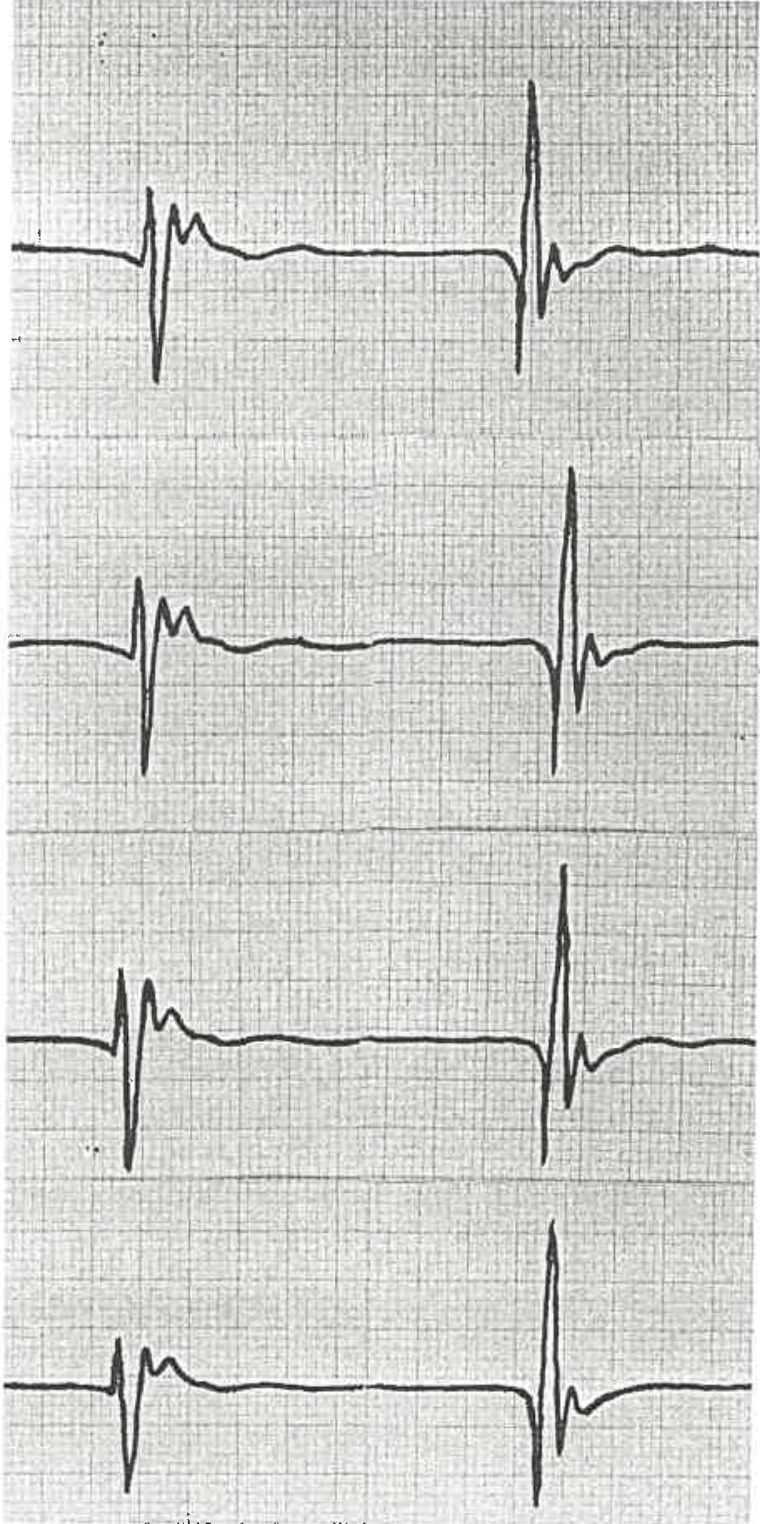

Fig. 4 Trigger Finger (25 mm/sec.). Flexion Extension

TABLE 2

Trigger Finger

\begin{tabular}{|c|c|c|c|c|c|c|}
\hline & \multicolumn{2}{|c|}{ Acceleration Range $(\mathrm{m} / \mathrm{s} / \mathrm{s})$} & \multicolumn{2}{|c|}{ R.M.S. $(\mathrm{m} / \mathrm{s} / \mathrm{s})$} & \multicolumn{2}{|c|}{ Peak Frequency (HZ.) } \\
\hline & Flexion & Extension & Flexion & Extension & Flexion & Extension \\
\hline \multicolumn{7}{|l|}{ (Subject $A$ ) } \\
\hline $\begin{array}{l}\text { Mean } \\
\text { Standard Deviation }\end{array}$ & $\begin{array}{l}33.860 \\
10.200\end{array}$ & $\begin{array}{l}34.306 \\
06.255\end{array}$ & $\begin{array}{l}02.796 \\
00.654\end{array}$ & $\begin{array}{l}02.802 \\
00.479\end{array}$ & $\begin{array}{l}41.260 \\
04.640\end{array}$ & $\begin{array}{l}63.611 \\
09.926\end{array}$ \\
\hline $\begin{array}{l}\text { (Subject B) } \\
\text { Mean } \\
\text { Standard Deviation }\end{array}$ & $\begin{array}{l}09.223 \\
02.650\end{array}$ & $\begin{array}{l}07.721 \\
02.443\end{array}$ & $\begin{array}{l}02.215 \\
00.388\end{array}$ & $\begin{array}{l}02.545 \\
01.070\end{array}$ & $\begin{array}{l}51.550 \\
11.620\end{array}$ & $\begin{array}{l}08.525 \\
01.583\end{array}$ \\
\hline $\begin{array}{l}\text { (Subject } C) \\
\text { Mean } \\
\text { Standard Deviation }\end{array}$ & $\begin{array}{l}11.520 \\
05.200\end{array}$ & $\begin{array}{l}07.527 \\
01.210\end{array}$ & $\begin{array}{l}02.200 \\
00.501\end{array}$ & $\begin{array}{l}01.769 \\
00.331\end{array}$ & $\begin{array}{l}02.750 \\
00.750\end{array}$ & $\begin{array}{l}06.750 \\
01.700\end{array}$ \\
\hline
\end{tabular}

VOL. 10-B No. 2 JUNE 1985 


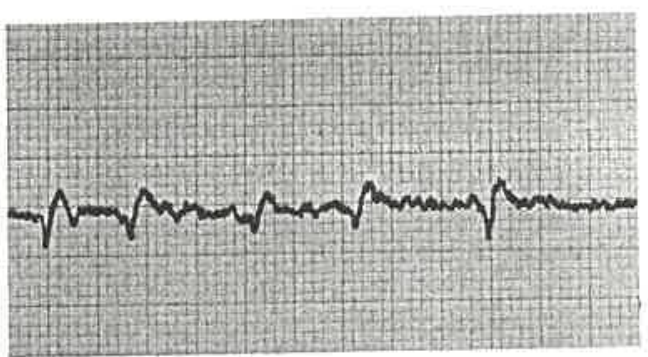

Fig. 5 Normal Low Amplitude Crepitus ( $25 \mathrm{~mm} / \mathrm{sec}$.$) .$

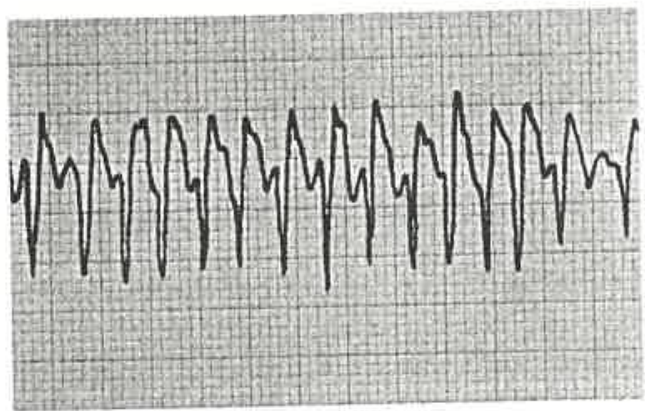

Fig. 6 Crepitus from Tenosynovitis $(25 \mathrm{~mm} / \mathrm{sec}$.).

\section{Illustrative Case Report}

A fifteen month old child (who had signs of rickets at birth, which responded to treatment with Vitamin D and One Alpha-hydroxy D3) presented to an experienced hand surgeon with a palpable click in both right and left middle fingers. The resulting discomfort made the child reluctant to move her middle fingers and the proximal interphalangeal joints tended to rest in ninety degrees of flexion. There was some difficulty in establishing a diagnosis as, although a tendon problem was most likely, the condition was bilateral and a joint abnormality could not be excluded. Despite the child's age there was no difficulty in listening to her hand using the method described. Under test a very distinct signal, corresponding to triggering energy was found. The hand was subsequently explored under general anaesthetic and the diagnosis of trigger finger was confirmed.
TABLE 3

Normal Low Amplitude Crepitus

\begin{tabular}{lccc}
\hline & $\begin{array}{c}\text { Acceleration } \\
\text { Range } \\
(\mathrm{m} / \mathrm{s} / \mathrm{s})\end{array}$ & R.M.S. & $\begin{array}{c}\text { Peak } \\
\text { Frequency } \\
(\mathrm{HZ} / \mathrm{s} / \mathrm{s})\end{array}$ \\
\hline Mean & 01.028 & 00.533 & 137.0 \\
Standard Deviation & 00.515 & 00.242 & 152.4 \\
\hline
\end{tabular}

TABLE 4

deQuervain's Tenosynovitis

\begin{tabular}{lccc}
\hline & $\begin{array}{c}\text { Acceleration } \\
\text { Range } \\
(\mathrm{m} / \mathrm{s} / \mathrm{s})\end{array}$ & R.M.S. & $\begin{array}{c}\text { Peak } \\
\text { Frequency } \\
(\mathrm{HZ} / \mathrm{s} / \mathrm{s})\end{array}$ \\
\hline Mean & 07.325 & 01.872 & 232.4 \\
Standard Deviation & 06.710 & 00.913 & 197.8 \\
\hline
\end{tabular}

\section{References}

“Any Questions?" (1969). British Medical Journal, 4: 351.

COWIE G. H. (1983). A Study of Screening Methods for Congenital Dislocation of the Hip, M.D. Thesis, Queen's University Belfast.

列 Queen's University Belfast. (1981).

MOLLAN, R. A. B., McCULLAGH, C. G., WILSON, R. I. (1984). Vibration Emission-A New Diagnostic Technique-In Press-Clinical Orthopaedics and Related Research.

ROSTON, J. B, and WHEELER HAINES, R. (1947). Cracking In The Mctacarpophalangeal Joint, Journal of Anatomy, 81: 165.-173.

STEINDLER, A. (1937). Auscultation Of Joints. The Journal of Bone and Joint Surgery, 19: 121-136.

UNSWORTH, A., DOWSON, D. and WRIGHT, V. (1971). 'Cracking Joints', A bion Annals of The Rheumatic Diseases, 30: 348-358.

UNSWORTH, A. The Cracking of Human Joints, Biopolymere Und Bir WALTERS, C. F. (1929). The Value of Joint Auscultation. The Lancet, 1: 920-921. 